\title{
Addressing hospital length of stay outlier patients: A community wide approach
}

\author{
Ronald Lagoe $^{1 *}$, Louise Pernisi ${ }^{2}$, Mary Luziani ${ }^{3}$, Shelly Littau ${ }^{1}$ \\ ${ }^{1}$ Hospital Executive Council, Syracuse, USA \\ ${ }^{2}$ Upstate University Hospital, SUNY UMU, Syracuse, USA \\ ${ }^{3}$ St. Joseph's Hospital Health Center, Syracuse, USA \\ Email: ${ }^{*}$ Hospexcl@cnymail.com
}

Received 7 December 2013; revised 7 January 2014; accepted 24 January 2014

Copyright (C) 2014 Ronald Lagoe et al. This is an open access article distributed under the Creative Commons Attribution License, which permits unrestricted use, distribution, and reproduction in any medium, provided the original work is properly cited. In accordance of the Creative Commons Attribution License all Copyrights (C) 2014 are reserved for SCIRP and the owner of the intellectual property Ronald Lagoe et al. All Copyright (C 2014 are guarded by law and by SCIRP as a guardian.

\section{ABSTRACT}

Length of stay outlier patients, who remain in hospitals for extended periods of time, is an important challenge to the improvement of health care efficiency. This study identified outlier patients and programs to address them in the metropolitan area of Syracuse, New York. It demonstrated that, during 2013, outlier patients accounted for $\mathbf{2 . 4}$ percent of adult medicine discharges and an excess average daily census of $\mathbf{5 3 . 3}$ patients in the Syracuse hospitals. During 2013, outlier patients accounted for 4.3 percent of adult surgery discharges and an excess average daily census of 44.1 patients. In two studies, the Syracuse hospitals identified the need for multiple intravenous therapy, extensive wound care, and total parenteral nutrition in the community, as major causes of outlier stays in hospitals. Each of the hospitals has developed a program with a long term care facility to address these needs. Efforts to address outlier lengths of stay are also focusing on Potentially Preventable Complications in Syracuse. The mean length of stay for inpatients with post admissions complications was almost three times the stay for the medical/surgical population during 2013.

\section{KEYWORDS}

\section{Hospital Utilization; Hospital Lengths of Stay;} Hospital Outcomes

\section{INTRODUCTION}

In the United States and elsewhere, the need for efficiency in the delivery of health care is growing in impor-

"Corresponding author. tance. Although efforts to reduce expenses in this sector have been a priority for decades, it has been suggested that the urgency of cost containment in this sector is increasing $[1,2]$.

In this context, health care payers have suggested that greater efficiency involves both reduction of utilization and improvement of the outcomes of services. Needs related to service utilization include reduction in hospital lengths of stay and inpatient admissions. Needs related to outcomes include reductions in inpatient complications and readmissions. Many of these issues are addressed by the concept of Accountable Care which is being advanced by Medicare [3-6].

With respect to both utilization and outcomes, an important challenge to improvement of efficiency is the outlier patient. It has been demonstrated that outlier patients, who use large amounts of health care resources, are associated with high utilization and adverse outcomes. Reduction of the use of health care by these individuals is one of the greatest challenges currently facing health care in the United States [3].

Historically, hospitals have used length of stay reduction to improve efficiency of utilization. Shorter stays and improved throughput have been associated with lower expenses for staffing, testing, and pharmaceuticals. Long stays consume much larger amounts of hospital resources for staffing, testing, and pharmaceuticals than do those of typical patients. Reduction of stays for them has been a major challenge because many communities lack facilities other than hospitals that can provide the care that these patients require after discharge [7].

It has also been demonstrated that outlier patients with adverse outcomes such as hospital complications are sources of excess expenses and inefficiency in hospitals. Studies involving administrative data have demonstrated 
that post admission complications, such as pneumonia, urinary tract infection, clostridium difficile colitis, and decubitus ulcer extend hospital stays and related expenses for staffing, supplies, and pharmaceuticals [8,9]. Many of these patients have high severity of illness.

In recent years, efforts to address outlier patients in hospitals have been supported by the development of computer software for analysis of administrative data. This software includes the All Patients Refined Severity of Illness and the Potentially Preventable Complications systems developed by $3 \mathrm{M}^{\mathrm{TM}}$ Health Information Systems [6].

Current experience suggests that, because health care is delivered within communities, efforts to address the needs of outlier patients will depend on provider efforts at the local level. This study described a series of efforts to identify and reduce numbers of outlier patients within the health care system of a small United States metropolitan area. The hospitals of this area made substantial gains in efficiency during the 1990s and the first years of the twenty first century. This study demonstrated how recent efforts to extend these gains encountered obstacles and generated new efforts to address them.

\subsection{Population and Method}

This study focused on the identification of length of stay outlier patients and development of programs to address them in the health care system of Syracuse, New York, a small metropolitan area located in Upstate New York. The health care system of this area serves a primary and secondary population of approximately 600,000. It also functions as the tertiary center for the eleven county Central New York Health Service Area, which includes a population of 1,400,000 (New York Statistical Information System, Unpublished Data, 2012).

The acute care system of Syracuse includes Crouse Hospital (20,719 inpatient discharges excluding well newborns-2012), St. Joseph's Hospital Health Center (26,219 discharges), and University Hospital of the State University of New York Upstate Medical University (27,621). During 2011, Upstate University Hospital acquired the then smallest acute care facility in Syracuse, Community General Hospital (Hospital Executive Council, Unpublished data, 2012).

Historically, the hospitals of Syracuse, New York have worked to reduce inpatient lengths of stay both individually and through their cooperative planning organization, the Hospital Executive Council. The first efforts addressing length of stay reduction involved hospital staffing and long term care resources [10].

\subsection{Identification and Evaluation of Hospital Inpatients with Long Lengths of Stay}

The initial component of the study focused on identi- fication of hospital outlier patients with long lengths of stay and large numbers of excess inpatient days. This analysis involved adult medicine and adult surgery patients, who account for more than 80 percent of inpatients in the Syracuse hospitals.

Within the two major services, the analysis identified inpatients with stays longer than 20 days discharged in January-September 2008 and January-September 2013, the latest seasonally adjusted periods for which complete data were available. For comparison purposes, patient populations with stays of 20 or fewer days for each of the services were also identified.

In order to quantify numbers of excess inpatient days for adult medicine and adult surgery, the analysis included comparison on inpatient stays in the Syracuse hospitals with stays for national hospital populations with the same inpatient severity of illness. In this analysis, the All Patients Refined Diagnosis Related Group Severity of Illness algorithm developed by the $3 \mathrm{M}^{\mathrm{TM}}$ Corporation was employed. This approach controlled for differences in stays produced by variations in the levels of illness of hospital patients.

This analysis involved identification of excess patient days for each of the two services at the unit and aggregate levels. The unit level was based on the difference between the each mean hospital stay and the severity adjusted national mean stay for the patient population with the same severity of illness. The aggregate excess days were based on the differences in mean stays multiplied by the numbers of discharges.

The analysis was carried out for the combined Syracuse hospitals and for each of the individual hospitals. Through the severity adjusted data, each population could be compared with the national average with the same severity of illness.

\subsection{Difficult to Place and Subacute Programs}

Prior to 2008, the Syracuse hospitals and the Hospital Executive Council had developed programs to address extended stays and excess patient days for medical/surgical patients. These included initiatives related to data distribution and incentives for nursing homes to admit specific types of these patients.

Programs involving data included a regional distribution of lists of hospital patients identified as Difficult to Place in long term care services. This weekly distribution identified, with names encrypted, characteristics of hospital patients determined to be Difficult to Place by each acute care management department. The distribution also included a monthly summary of Difficult to Place patients admitted to area nursing homes and rates of admission per total new admissions [11].

Based on the Difficult to Place information, the Syracuse hospitals developed a series of Subacute Programs 
to address specific obstacles to the discharge patients from acute care facilities, such as the need for intravenous and other high cost medications, extensive wound care, bariatric care, and other programs. They were implemented through the program development funds channelled by the hospitals through the Hospital Executive Council to long term care facilities [7].

This study included data concerning use of these programs between 2008 and 2013. This information was compared with the length of stay data identified previously.

\subsection{Complex Care (Long Term Acute Care)}

Since 2010, the Syracuse hospitals and the Hospital Executive Council have pursued a second generation of length of stay reduction efforts for adult medicine and adult surgery. These initiatives have involved different aspects of the remaining excess days. Experience suggests that these efforts have addressed increasing challenges because the remaining excess patient days were not eliminated through previous initiatives. Their progress has been evaluated through comparisons of aggregate hospital stays with severity adjusted national averages.

Historically, a component of extended stays in the Syracuse hospitals resulted from patients requiring complex long term acute care services such as multiple intravenous antibiotics, extensive wound care, and ventilator therapy. In a number of states, these services are known as long term acute care, after the programs that were developed to address them. In New York State, a separate reimbursement mechanism has not been developed and these complex care services must be reimbursed through existing hospital reimbursement.

In order to address the potential for length of stay reduction through Complex Care, the Hospital Executive Council conducted two analyses of these services in the Syracuse hospitals, a twelve month analysis for patients discharged between June 2009 and May 2010 and a followup, two month analysis for patients discharged between December 2011 and January 2012.

In each of these studies, the patient population identified included discharges with inpatient stays for 26 days or more in the Syracuse hospitals. For these discharges the $3 \mathrm{M}^{\mathrm{TM}}$ All Patients Refined System was employed to identify the number of days exceeding national averages for patients with the same severity of illness. The analyses were carried out by the Hospital Executive Council staff.

For the discharges identified, detailed information concerning care requirements and related resources was collected from hospital medical records. These resources included nursing and other staff time, supplies and pharmaceuticals. These data were collected by care manage- ment nurses at each hospital.

This study included services identified in the Complex Care studies as generating excess hospital stays and patient days in the Syracuse hospitals. It also identified services that were later planned and implemented by each of the hospitals and the Hospital Executive Council to address them.

\subsection{Hospital Stays Related to Inpatient Complications}

Another aspect of length of stay reduction in the Syracuse hospitals has involved increased attention to the improvement of health care outcomes that has developed in recent years. Research literature based on administrative data has demonstrated that improved outcomes such as lower post admission complication rates are frequently associated with shorter stays and lower use of hospital resources such as pharmaceuticals and diagnostic testing $[8,12]$.

Beginning in 2008, a number of the Syracuse hospitals, the Hospital Executive Council, and $3 \mathrm{M}^{\mathrm{TM}}$ Health Information Services developed a program to reduce inpatient hospital readmissions and related resource use based on the Potentially Preventable Complications software. With this program, the Hospital Executive Council staff was able to identify numbers of excess days for each of specific post admission complication. These included high volume diagnoses such as pneumonia and urinary tract infection, and lower volume ones, such as clostridium difficile colitis and decubitus ulcer [9].

This study identified excess utilization associated with extended lengths of stay associated with inpatient complications in St. Joseph's Hospital Health Center. This included excess stays and inpatient days for two high volume post admission complications, pneumonia and urinary tract infection, and one low volume complication, clostridium difficile colitis between January and September 2013.

\section{RESULTS}

The results of the study involved development of data for each of the study components in the Syracuse hospitals.

\subsection{Identification and Evaluation of Patients with Long Lengths of Stay}

Data related to identification of patients with long lengths of stay for adult medicine and adult surgery are summarized in Tables 1 and 2.

This information demonstrates the long stay patients comprised a small proportion of hospital discharges for adult medicine and adult surgery in the Syracuse hospitals. For adult medicine, this proportion ranged from 2.0 to 2.4 percent of the total between 2008 and 2013. For 
Table 1. Inpatient adult medicine mean lengths of stay, Syracuse Hospitals, January-September 2008-2013.

\begin{tabular}{|c|c|c|c|c|c|}
\hline & \multicolumn{5}{|c|}{ Patients w Length of Stay > 20 Days } \\
\hline & $\begin{array}{l}\text { Number of } \\
\text { Discharges }\end{array}$ & $\begin{array}{l}\text { Mean Length } \\
\text { of Stay }\end{array}$ & $\begin{array}{l}\text { Severity Adjusted } \\
\text { National Average }\end{array}$ & $\begin{array}{l}\text { Length of Stay } \\
\text { Difference }\end{array}$ & $\begin{array}{l}\text { Patient Days } \\
\text { Difference }\end{array}$ \\
\hline \multicolumn{6}{|l|}{ January-September 2008} \\
\hline Crouse Hospital & 114 & 28.89 & 8.44 & 20.45 & 2331.30 \\
\hline St. Joseph’s Hospital & 112 & 31.71 & 9.33 & 22.38 & 2506.56 \\
\hline \multicolumn{6}{|l|}{ Health Center } \\
\hline Upstate University Hospital & 214 & 31.68 & 8.33 & 23.35 & 4996.90 \\
\hline \multicolumn{6}{|l|}{ SUNY UMU } \\
\hline Total & 440 & 30.97 & 8.61 & 22.36 & 9838.40 \\
\hline \multicolumn{6}{|l|}{ January-September 2013} \\
\hline Crouse Hospital & 112 & 30.38 & 9.76 & 20.62 & 2309.44 \\
\hline St. Joseph’s Hospital & 207 & 32.02 & 9.33 & 22.69 & 4696.83 \\
\hline \multicolumn{6}{|l|}{ Health Center } \\
\hline Upstate University Hospital & 309 & 33.16 & 9.65 & 23.51 & 7264.59 \\
\hline \multicolumn{6}{|l|}{ SUNY UMU } \\
\hline \multirow[t]{2}{*}{ Total } & 628 & 32.29 & 9.57 & 22.72 & $14,268.16$ \\
\hline & \multicolumn{5}{|c|}{ Patients with Length of Stay $<21$ Days } \\
\hline \multicolumn{6}{|l|}{ January-September 2008} \\
\hline Crouse Hospital & 5747 & 4.57 & 4.57 & 0.00 & 0.00 \\
\hline St. Joseph’s Hospital & 7295 & 4.19 & 4.70 & -0.51 & $-3,720.45$ \\
\hline \multicolumn{6}{|l|}{ Health Center } \\
\hline Upstate University Hospital & 8068 & 4.56 & 4.42 & 0.14 & 1129.52 \\
\hline \multicolumn{6}{|l|}{ SUNY UMU } \\
\hline Total & 21,110 & 4.44 & 4.56 & -0.12 & -2533.20 \\
\hline \multicolumn{6}{|l|}{ January-September 2013} \\
\hline Crouse Hospital & 6069 & 4.52 & 5.26 & -0.74 & -4491.06 \\
\hline St. Joseph’s Hospital & 9442 & 4.55 & 4.90 & -0.35 & -3304.70 \\
\hline \multicolumn{6}{|l|}{ Health Center } \\
\hline Upstate University Hospital & 9824 & 4.41 & 4.98 & -0.57 & -5599.68 \\
\hline \multicolumn{6}{|l|}{ SUNY UMU } \\
\hline Total & 25,335 & 4.49 & 5.02 & -0.53 & $-13,427.55$ \\
\hline
\end{tabular}

Sources: Crouse Hospital, St. Joseph’s Hospital Health Center, and Upstate University Hospital-SUNY UMU; National Hospital Discharge Study.

adult surgery, the proportion ranged from 4.9 to 4.3 percent of the total. Between the two years, the proportion increased for adult medicine and declined for adult surgery, related to an increase in the number of medicine patients and a decline in the number of surgery patients.

The study data demonstrated that the limited numbers of long stay patients in the Syracuse hospitals generated disproportionate levels of inpatient hospital patient days. 
Table 2. Inpatient adult surgery mean lengths of stay, Syracuse Hospitals, January-September 2008-2013.

\begin{tabular}{|c|c|c|c|c|c|}
\hline & \multicolumn{5}{|c|}{ Patients with Length of Stay $>20$ Days } \\
\hline & $\begin{array}{l}\text { Number of } \\
\text { Discharges }\end{array}$ & $\begin{array}{c}\text { Mean Length } \\
\text { of Stay }\end{array}$ & $\begin{array}{l}\text { Severity Adjusted } \\
\text { National Average }\end{array}$ & $\begin{array}{l}\text { Length of Stay } \\
\text { Difference }\end{array}$ & $\begin{array}{c}\text { Patient Days } \\
\text { Difference }\end{array}$ \\
\hline \multicolumn{6}{|l|}{ January-September 2008} \\
\hline Crouse Hospital & 97 & 38.22 & 16.85 & 21.37 & 2072.89 \\
\hline St. Joseph’s Hospital & 242 & 45.00 & 19.63 & 25.37 & 6139.54 \\
\hline \multicolumn{6}{|l|}{ Health Center } \\
\hline Upstate University Hospital & 368 & 38.45 & 17.69 & 20.76 & 7639.68 \\
\hline \multicolumn{6}{|l|}{ SUNY UMU } \\
\hline Total & 707 & 40.66 & 18.24 & 22.42 & $15,850.94$ \\
\hline \multicolumn{6}{|l|}{ January-September 2013} \\
\hline Crouse Hospital & 89 & 34.80 & 17.87 & 16.93 & 1506.77 \\
\hline St. Joseph’s Hospital & 250 & 36.58 & 19.40 & 17.18 & 4295.00 \\
\hline \multicolumn{6}{|l|}{ Health Center } \\
\hline Upstate University Hospital & 325 & 40.20 & 20.94 & 19.26 & 6259.50 \\
\hline \multicolumn{6}{|l|}{ SUNY UMU } \\
\hline \multirow[t]{2}{*}{ Total } & 664 & 38.11 & 19.95 & 18.16 & $12,058.24$ \\
\hline & \multicolumn{5}{|c|}{ Patients with Lengths of Stay $<21$ Days } \\
\hline \multicolumn{6}{|l|}{ January-September 2008} \\
\hline Crouse Hospital & 3267 & 3.85 & 4.56 & -0.71 & -2319.57 \\
\hline St. Joseph’s Hospital & 5189 & 4.47 & 5.24 & -0.77 & -3995.53 \\
\hline \multicolumn{6}{|l|}{ Health Center } \\
\hline Upstate University Hospital & 5366 & 4.87 & 4.89 & -0.02 & -107.32 \\
\hline \multicolumn{6}{|l|}{ SUNY UMU } \\
\hline Total & 13,822 & 4.48 & 4.94 & -0.46 & -6358.12 \\
\hline \multicolumn{6}{|l|}{ January-September 2013} \\
\hline Crouse Hospital & 3395 & 3.74 & 4.77 & -1.03 & -3496.85 \\
\hline St. Joseph’s Hospital & 6859 & 4.22 & 5.07 & -0.85 & -5830.15 \\
\hline \multicolumn{6}{|l|}{ Health Center } \\
\hline Upstate University Hospital & 4379 & 5.20 & 6.00 & -0.80 & -3503.20 \\
\hline \multicolumn{6}{|l|}{ SUNY UMU } \\
\hline Total & 14,633 & 4.40 & 5.28 & -0.88 & $-12,877.04$ \\
\hline
\end{tabular}

Sources: Crouse Hospital, St. Joseph's Hospital Health Center, and Upstate University Hospital-SUNY UMU; National Hospital Discharge Study.

For adult medicine, the unit difference between the stays for this population and the severity adjusted national average increased slightly from 22.36 to 22.72 days. When multiplied by the increasing numbers of these pa- tients, this caused the total number of excess days for the service to increase by 45 percent, from 9838 to 14,268. This amounted to community wide excess daily census of 35.9 to 53.3 patients. 
For adult surgery, the unit difference between the hospital stay and the severity adjusted national average declined from 22.42 to 18.16 days. This decline, combined with a reduction in the numbers of long stay patients, caused the number of excess days for this population to decline by 23.9 percent, from 15,850 to 12,058 . This still amounted to a community wide excess average daily census of 57.8 to 44.1 patients.

These developments were reflected in the institution specific data for most of the Syracuse hospitals. For adult medicine, the numbers of patients with stays greater than 20 days increased for the two hospitals with the largest numbers of adult medicine discharges, St. Joseph's Hospital Health Center and University Hospital. For adult surgery, numbers of long stay patients declined for Crouse Hospital and Upstate University Hospital. The increase in long stay patients at St. Joseph's Hospital Health Center was probably related to an increase in the adult surgery population.

Most importantly, the long stay patients caused each of the individual hospitals to generate substantial levels of excess inpatient days. For adult medicine, these hospital specific levels ranged from 20 to more than 23 days in both time periods. For adult surgery, the hospital specific levels ranged from 20 to more than 25 days in 2008 and from 16 to more than 19 days in 2013. The unit differences caused these limited populations, less than 3 percent of adult medicine inpatients and less than 5 percent of adult surgery inpatients, to produce thousands of excess days in the Syracuse hospitals.

The relative impact of the long stay patients was also reflected in the comparison of excess days with those of patients who stayed 20 days of less. For adult medicine, the numbers of excess days for the long stay population offset the numbers of days below the severity adjusted national averages for the shorter stay population for both time periods. For adult surgery, the impact was similar. A reduction in excess days and an increase in days saved caused the two levels to be nearly equal in 2013 .

The impact of the excess patient stays for the long stay patients was also reflected in the experiences of the individual hospitals. In 2013, the large numbers of excess days for long stay patients were offsetting most or all of the days saved for the two services.

\subsection{Difficult to Place and Subacute Programs}

As suggested in the Methods section, the impact of the Difficult to Place and Subacute Programs in the Syracuse hospitals between 2008 and 2013 probably supported reductions in stays for the population that was discharged in 20 days or fewer days. Reductions in stays for this group are identified in Tables 1 and 2 .

The data in Table 3 indicate that the use of these programs increased between 2008 and 2013. This was de- monstrated by increases in the number of Difficult to Place patients admitted to nursing homes and the percent of new nursing homes that were at this level.

Comparison of this information with the data in Tables 1 and 2 suggests that the increases in difficult to place placements in long term care facilities in the Syracuse area probably did not reduce the amount of excess stays and utilization for patients who stayed longer than 20 days. The structures of these programs probably did not address the specific needs of this outlier population.

\subsection{Complex Care (Long Term Acute Care)}

Between 2010 and 2012, the Syracuse hospitals conducted two major studies that identified service needs related to length of stay outliers. These services and related numbers of discharges and excess patient days, as well as the content of hospital Complex Care programs, are identified in Table 4.

This information suggests that the service needs of Complex Care patients in the Syracuse hospitals were relatively consistent between the two studies. In both studies, the largest numbers of excess patient days were associated with patients who required multiple intravenous therapy. The need for extensive wound care and total parenteral nutrition also generated considerable numbers of excess days. All of these services could not be addressed by the individual services provided by the subacute programs in long term care facilities.

These combinations of services also reflected the needs of the individual hospitals. Numbers of excess days were highest at St. Joseph's Hospital Health Center and Upstate University Hospital, which discharge the largest numbers of medical and surgical inpatients.

Beginning in 2012, the Syracuse hospitals and the Hospital Executive Council have developed Complex Care programs in cooperation with local long term care facilities to address these needs. The St. Joseph's Hospital Health Center program which involves Loretto, the largest long term care facility in the area, began in March 2012. The Upstate University Hospital program, in cooperation with St. Camillus Health and Rehabilitation Center, started in September 2013. The Crouse Hospital program, in cooperation with James Square Health and Rehabilitation Center, began in November 2013. All of these programs address multiple intravenous medications and wound care. A major Complex Care service that remains to be developed in nursing homes in Syracuse is total parenteral nutrition.

\subsection{Hospital Stays Related to Inpatient Complications}

The efforts of the Syracuse hospitals and the Hospital Executive to Council to address patients with outlier 
Table 3. Difficult to place nursing home placements, Syracuse Hospitals, 2008-2013.

\begin{tabular}{|c|c|c|c|c|c|c|}
\hline \multirow[b]{2}{*}{ Nursing Home } & \multicolumn{3}{|c|}{ Number of Difficult to Place Patients } & \multicolumn{3}{|c|}{ Rate Per New Admissions to Nursing Homes } \\
\hline & 2008 & 2013 & Difference & 2008 & 2013 & Difference \\
\hline & \multicolumn{3}{|c|}{ Annualized } & \multicolumn{3}{|c|}{ Annualized } \\
\hline Birchwood Health Care Ctr & 24 & 29 & 5 & 3.5 & 5.5 & 2.0 \\
\hline Central Park & 76 & 52 & -24 & 58.9 & 42.2 & -6.7 \\
\hline The Crossings & 21 & 32 & 11 & 10.0 & 18.1 & 8.1 \\
\hline Iroquois Nursing Home & 85 & 173 & 88 & 23.4 & 39.0 & 15.6 \\
\hline James Square Nursing Home & 137 & 238 & 101 & 33.2 & 55.5 & 22.3 \\
\hline Jewish Home of C.N.Y. & 11 & 16 & 5 & 5.0 & 10.5 & 5.5 \\
\hline Loretto & 171 & 278 & 107 & 18.2 & 32.8 & 14.6 \\
\hline Rosewood Heights & 157 & 128 & -29 & 42.0 & 53.5 & 11.5 \\
\hline St. Camillus Hlth. Reh. Ctr. & 92 & 197 & 105 & 12.6 & 27.3 & 14.7 \\
\hline Sunnyside Nursing Home & 13 & 54 & 41 & 17.6 & 30.0 & 12.4 \\
\hline Syracuse Home Association & 11 & 32 & 21 & 3.5 & 7.7 & 4.2 \\
\hline Van Duyn Home and Hospital & 86 & 112 & 26 & 26.5 & 32.3 & 5.8 \\
\hline Out of County & 280 & 586 & 306 & 19.3 & 27.6 & 8.3 \\
\hline Total & 1164 & 1927 & 763 & 18.7 & 28.6 & 9.9 \\
\hline
\end{tabular}

2013 Data annualized based on January-October 2013 actual experience. Rates are based on actual difficult to place admissions divided by total new admissions. Difficult to place admissions included returns for this period. Source: Hospital Executive Council.

Table 4. Complex care patient studies and programs, Syracuse Hospitals.

\begin{tabular}{lccccc}
\hline & $2010-2011$ Study & \multicolumn{3}{c}{ 2011-2012 Study } \\
\hline & $\begin{array}{c}\text { Number } \\
\text { of } \\
\text { Discharges }\end{array}$ & $\begin{array}{c}\text { Annual } \\
\text { Excess } \\
\text { Days }\end{array}$ & $\begin{array}{c}\text { Number } \\
\text { of } \\
\text { Discharges }\end{array}$ & $\begin{array}{c}\text { Excess } \\
\text { Days }\end{array}$ & $\begin{array}{c}\text { Annualized } \\
\text { Excess } \\
\text { Days }\end{array}$ \\
\hline Required Service & & & & & \\
Multiple IV’s & 133 & 3478 & 50 & 1279 & 7674 \\
Wound Care & 81 & 2562 & 4 & 125 & 750 \\
Nutrition/TPN & 35 & 852 & 12 & 336 & 2016 \\
Chemotherapy & 46 & 990 & 7 & 158 & 948 \\
Dialysis & 20 & 606 & 1 & 15 & 90 \\
Mental Health & 31 & 1164 & 2 & 180 & 1080 \\
\hline
\end{tabular}

Sources: Hospital Executive Council; 3M Health Information Systems.

lengths of stay also involved inpatients with Potentially Preventable Complications. Related data for medical surgical patients at St. Joseph's Hospital Health Center, the Syracuse acute care facility with the largest inpatient volume, are summarized in Table 5.

This information demonstrates that inpatients at the hospital with post admission complications generated lengths of stay that were considerably longer than those of the medical/surgical population. Between January and September, the mean length of stay of total inpatients with complications was 15.38 days, almost three times the stay for the medical/surgical population. If the patients with complications had experienced stays at the total rate, 6778 days, or an average daily census of 24.8 patients would have been saved between January and September 2013.

The data in Table 5 also demonstrated that mean stays at the hospital for the three post admission complications identified pneumonia and urinary tract infection were 23 to 94 percent longer than those of total medical/surgical inpatients with complications. Of these diagnoses, pneumonia and urinary tract infections were complications with the highest volumes, both locally and nationally.

The demonstration program involving the Hospital Executive Council and $3 \mathrm{M}^{\mathrm{TM}}$ Health Information Systems has supported notable reductions in inpatient complications at St. Joseph's Hospital Health Center between 2009 and 2013. During this period, the rate of complications per 1000 inpatient discharges and related lengths of stay declined from 54.02 to 39.07 . The study data suggest that considerable opportunities exist for further reduction of these adverse outcomes and related hospital 
Table 5. Hospital inpatient utilization, potentially preventable complication patients, St. Joseph's Hospital Health Center, January-September 2013.

\begin{tabular}{lccc}
\hline & Number of Discharges & Number of Patient Days & Mean Length of Stay \\
\hline Total Medical/Surgical Patients & 16,758 & 87,701 & 5.23 \\
Total Patients w Complications & 665 & 10,225 & 15.38 \\
Pneumonia Complications Patients & 160 & 3128 & 19.55 \\
Urinary Tract Infection Complications Patients & 77 & 2309 & 29.99 \\
Clostridium Difficile Colitis Complications Patients & 49 & 993 & 20.27 \\
\hline
\end{tabular}

Sources: Hospital Executive Council; 3M Health Information Systems

utilization.

\section{DISCUSSION}

In recent years, increased interest in addressing health care outcomes has been reflected in the often repeated saying, "It's all about outcomes". For those familiar with the specifics of health care utilization, such as those identified in this study, the operative phrase might instead be, "It's all about outliers".

This study demonstrated how limited numbers of length of stay outliers could have a disproportionate impact on hospital utilization at the community wide level. In the Syracuse hospitals during the first three quarters of 2013, patients who stayed longer than 20 days accounted for more than 14,000 excess inpatient days compared with the severity adjusted national average, but only 2.5 percent of the adult medicine population. These patients accounted for more than 9800 excess days, compared with severity adjusted national averages, but only 4.5 percent of the adult surgery population. These differences were also reflected in the experiences of the individual Syracuse hospitals. For the combined services, the total excess days amounted to an average daily census of 100 patients.

The data also demonstrated that, at least in Syracuse, the challenge of length of stay outliers is not going away. Between 2008 and 2013, excess days for adult medicine outliers increased by 45 percent. Excess days for adult surgery outlier declined but were still more than 12,000 days for a nine month period in 2013. Inpatient complications were also generating thousands of excess days for patients who stayed more than three times a hospital average.

In order to address the challenges of the outlier population, the Syracuse hospitals have assembled a number of resources. Among the most important of these are the All Patients Refined Severity of Illness and the Potentially Preventable Complications Software developed by $3 \mathrm{M}^{\mathrm{TM}}$ Health Information Services. These tools have enabled the hospitals to identified excess stays related to utilization and outcomes with a high degree of accuracy.
At the programmatic level, the Syracuse hospitals have developed initiatives to address the needs of outlier patients. Some of them, such as the Difficult to Place and Subacute Programs, do not have the ability to address the levels of service required by recent outlier patients.

The impacts of programs developed more recently on hospital outlier patients in Syracuse are a work in progress. The St. Joseph's Hospital Health Center Complex Care Program has shifted pharmaceutical therapy stays for a number of patients outside the hospital, but not enough to produce a reduction in aggregate lengths of stay for outlier patients. The Complex Care programs at Upstate University Hospital and Crouse Hospital have been implemented recently and will require more time to evaluate. The program for reducing inpatient complications at St. Joseph's Hospital Health Center has reduced complications rates, but remaining patients with these adverse outcomes are still generating thousands of excess days.

The magnitude and content of the length of stay outlier problem in Syracuse suggest that this effort will require considerable resources and focused efforts over time. If the interests of these patients and the health care systems that serve them are to be addressed as they should be, hospitals will need to develop and sustain these initiatives. If hospitals throughout the nation share this view, they have the opportunity to share their experiences and make meaningful contributions to the needs of the outlier population.

\section{REFERENCES}

[1] Dentzler, S. (2011) Urgent measures for an old problem. Health Affairs, 30, 1626. http://dx.doi.org/10.1377/hlthaff.2011.0961

[2] Auerbach, D.L. and Kellerman, A.L. (2011) A decade of health care cost growth has wiped out real income gains for an average US family. Health Affairs, 30, 1626. http://dx.doi.org/10.1377/hlthaff.2011.0585

[3] Evans, M. (2012) The early returns on accountable care. Modern Healthcare, 42, S1-S5. 
[4] Fisher, E.S., Shortell, S.M., Kriendler, S.A., Van Citters, A.D. and Larson, B.K. (2012) A framework for evaluating the formation, implementation, and performance of Accountable Care Organizations. Health Affairs, 31, 2368-2378. http://dx.doi.org/10.1377/hlthaff.2012.0544

[5] Hoffman, E.D., Klees, B.S. and Curtis, C.A. (2001) Overview of the medicare and medicaid programs. Health Care Financing Review, Statistical Supplement 1-102.

[6] 3M Health Information Systems. (2009) Potentially preventable events. 3M Health Information Systems, Wallingford, Conn.

[7] Lagoe, R.J., Westert, G.P., Kendrick, K., Morreale, G. and Mnich, S. (2005) Managing hospital length of stay reduction: A multihospital approach. Health Care Management Review, 30, 82-92. http://dx.doi.org/10.1097/00004010-200504000-00002

[8] Fuller, R.L., McCullough, E.C., Bao, M.Z. and Averill, R.F. (2009) Estimating the costs of potentially preventable hospital complications. Health Care Financing Review, 30, 17-32.
[9] Lagoe, R.J., Johnson, P.E. and Murphy, M.P. (2011) Inpatient hospital complications and lengths of stay: A short report. BMC Research Notes, 4, 135. http://dx.doi.org/10.1186/1756-0500-4-135

[10] Lagoe, R.J., Altwarg, J.D. and Noetscher, C.M. (2005) Development and implementation of a community-wide infusion therapy program by hospitals and nursing homes in Syracuse, New York. Journal of Infusion Therapy, 28, 1-7.

[11] Lagoe, R.J., Noetscher, C., Markle, A. and Johnson, P. (2010) Community-wide programs to support hospital discharges to nursing homes 2010. Topics in Advanced Practice Nursing eJournal, 10.

[12] Hoonhout, L.H., deBruijne, M.C., Wagner, C., Zegers, M., Waaijman, R., Spreeuwenberg, P., Asscherman H., van der Wal, G. and Tulder van, M.W. (2009) Direct medical costs of adverse events in Dutch hospitals. BMC Health Services Research, 9, 27. http://dx.doi.org/10.1186/1472-6963-9-27 